\title{
RAPID ASSESSMENT OF KEY STRUCTURAL ELEMENTS OF DIFFERENT VEGETATION TYPES OF WEST AFRICAN SAVANNAS IN BURKINA FASO
}

\author{
MOHAMMAD QASIM $^{1}$, SteFAn POREMBSKI $^{2}$, KATHARINA STEIN $^{3}$, \\ *ANDRÉ LINDNER ${ }^{4}$
}

\begin{abstract}
${ }^{1}$ Institute of International Forestry and Forest Products, Technische Universität Dresden, Pienner Strasse 7, 01737 Tharandt, Germany

${ }^{2}$ Department of Botany, Institute of Biological Sciences, University of Rostock, Wismarsche Str. 8, 18051 Rostock

${ }^{3}$ Department of Animal Ecology and Tropical Biology, University of Wuerzburg, Josef-Martin-Weg 52, 97074 Wuerzburg, Germany

${ }^{4}$ *entre for International Postgraduate Studies of Environmental Management CIPSEM, Technische Universität Dresden, Zellescher Weg 41c, 01207 Dresden, Germany, email: andre.lindner@tu-dresden.de, *corresponding author
\end{abstract}

Received: $6^{\text {th }}$ January 2016, Accepted: $26^{\text {th }}$ April 2016

\begin{abstract}
Estimations of Leaf Area Index (LAI) have recently gained attention due to the sensitivity to the effects of climate change and its impact on forest ecosystems. Hence, a study was conducted on the LAI estimation of four vegetation types: (i) gallery forests, (ii) woodland savannas, (iii) tree savannas, and (iv) shrub savannas, at two protected areas of Nazinga Game Ranch and Bontioli Nature Reserve, Burkina Faso. A relationship between LAI and Crown Diameter was also investigated at these two sites. Digital hemispherical photography was used for the LAI estimation. Crown diameters (CD) were determined perpendicular to each other and averaged for each tree and shrub. Overall results revealed that LAI ranged from $0-1.33$ and the $C D$ was recorded in the range of $0.46-11.01 \mathrm{~m}$. The gallery forests recorded the highest mean LAI $1.33 \pm 0.32$ as well as the highest mean CD $7.69 \pm 1.90 \mathrm{~m}$. The LAI for the vegetation types were at their lower ends as the study was conducted in summer season, higher values are therefore expected in the wet season, as a significant correlation between LAI and precipitation has been emphasized by various studies. Continuous LAI monitoring and studies on various growth parameters of different vegetation types at the study sites are recommended towards enhanced monitoring and an ecologically feasible forest- and savanna-use and management to maintain essential ecosystem functions and services.
\end{abstract}

Keywords: leaf area index, crown diameter, savanna vegetation, hemispherical photography

\section{INTRODUCTION}

The Leaf Area Index (LAI) is defined as the half of the total green leaf area per unit of horizontal ground surface area (Chen \& Black, 1992). Recently, it has been receiving more 
attention because of the increasing demands of forest growth parameters estimates in the light of forests role in carbon sequestration (Mustafa et al. 2014). LAI is a dimensionless variable (Fieber et al., 2014). It is also helpful in the identification of canopy structural responses to competitions, diseases and climate change. It can be measured through direct contact i.e. (destructive sampling of leaves) and by indirect optical methods (i.e. hemispherical photography, measurements of radiation through canopy) (Weiss et al., 2004).

Digital hemispherical photography (DHP) has been used as an indirect method for LAI estimation since 1970s and has also gained resurgence with the development of photographic and processing technology in recent years (Nfon et al., 2011). DHP has various advantages compared to other direct and indirect LAI estimation methods such as low processing time, low financial expenditures, ease of operation and possibility of establishing a permanent record of canopy formation (Zhao et al., 2014). DHP has, therefore, been used for many canopy types ranging from tall trees to small shrubs and herbaceous canopies (Chianucci \& Cutini, 2013). And it is considered an important tool for assessments of canopy structures (Lindner, 2011).

A very essential part of forest physiognomic research is the development of allometric equations between LAI and various biophysical parameters such as Crown Diameter (CD) (Vyas et al., 2010). Biophysical relationships can be helpful in estimating LAI without the use of the destructive sampling (Jonckheere et al., 2004). These estimations through allometric relationships have also been emphasized for their accuracy in comparison to the use of complex models and expensive methods such as DHP etc. (Pompelli et al., 2012). Many studies have shown relationships between LAI and different biophysical parameters for various trees species, too (Arias et al., 2007).

Our study investigates the LAI in the vegetation types of two protected areas in Burkina Faso: Nazinga Game Ranch and Bontioli Nature Reserve. The need is also aggravated due to scarcity of the data on LAI for tropical savannah regions (Unger et al., 2013). Our study also investigates the relationship between LAI and CD (m), which will therefore help in designing appropriate management strategies for the two above mentioned protected areas in the future (Khosravi et al., 2012).

\section{MATERIALS AND METHODS}

\section{Study Sites}

The Nazinga Game Ranch is a protected area, classified as "Wildlife Reserve" according to the Burkina Faso's legislation. It is spread over an area of 97,536 ha (Hema et al., 2011). It was created back in 1979 (Vermeulen et al., 2010). The area is a very well known tourist attraction (Kristensen \& Balslev, 2003).

The Nazinga Game Ranch has a single dry season from October to May and a single rainy season from June to September each year. The mean annual rainfall is $900 \mathrm{~mm}$ (Hema et al., 2011). The mean altitude is $280 \mathrm{~m}$ (Jenks et al., 2007). The mean temperature is $28^{\circ} \mathrm{C}$ for the period 2000 to 2010 (MSP, 2010). It is traversed by the Sessile River and its two tributaries i.e. the Dawevele and the Nazinga Rivers, which are marked by their seasonal flows.

The vegetation of Nazinga Game Ranch has the characteristics of Southern Sudanian savanna. The vegetation includes Vitellaria paradoxa C.F. Gaertn., Terminalia laxiflora Engl. \& Diels, Gardenia erubescens Stapf \& Hutch., Afzelia africana Sm., Anogeissus leiocarpa (DC.) Guill. \& Perr. etc. (Dekker, 1985). Similarly, representative plant families include Caesalpiniaceae, Combretaceae, Rubiaceae, Celastraceae, Rubiaceae, Mimosaceae, Apocynaceae, Bignoniaceae, Sapotaceae and Ebenaceae. 
The Nazinga Game Ranch has been divided into four zones i.e. Conservation Zone, Buffer Zone, Hunting Zone and Village Hunting Zone, for management purposes. The Conservation Zone consists of 9\%, Buffer Zone 5\% and the Hunting Zone and the Village Hunting Zone together form $86 \%$ of the total area (Jenks et al., 2007). There are few villages located in the Hunting Zone and Village Hunting Zone. The Nazinga Game Ranch once had been known to be one of the least populated areas in Burkina Faso (Hema et al., 2011). But the Sahelian droughts in 1970s resulted in the increasing migrations in this area (Hema et al., 2011). The agriculture has been the major source of subsistence for the local people, with major crops being Zea mays L., Sorghum bicolor (L.) Moench, Pennisetum glaucum (L.) R. Br., Arachis hypogaea L., Gossypium barbadense L.

The Bontioli Nature Reserve is also a protected area, categorized as a "Nature Reserve" according to the Burkina Faso's legislation (Tia, 2007). It is situated in the province of Bougouriba and lies within the Volta basin (Tia, 2007). It is spread over an area of 25,000 ha (Tia, 2007). The Bontioli Nature Reserve was created in 1957 (Von Buschfeuern, 2010). It is located $280 \mathrm{~km}$ away from the capital city of Ouagadougou, $35 \mathrm{~km}$ south of Dano, a small town in Burkina Faso.

The vegetation of the Bontioli Nature Reserve has the characteristics of the Southern Sudanian savanna. The rainy season is from May to October and the dry season from November to April (Grote et al., 2009). The rainfall is between 900-1000 mm year ${ }^{-1}$ (Tia, 2007). The mean temperature of $27.1^{\circ} \mathrm{C}$ has been recorded for the period of 2004-2006. The main river is the Bougouriba, responsible for governing the hydrographical network within the Bontioli Nature Reserve (Tia, 2007). The river is spread over the length of $406 \mathrm{~km}$ having a slope of $0.2 \mathrm{~m} \mathrm{~km}^{-1}$ (Moniod et al., 1977). The highest altitude is $350 \mathrm{~m}$ and the lowest altitude is $250 \mathrm{~m}$.

The tree species of the Bontioli Nature Reserve include Burkea africana Hook., Pterocarpus erinaceus Poir., Crossopteryx febrifuga (Afz. ex G. Don) Benth., Combretum glutinosum Perr. ex DC. etc.. Similarly, the representative plant families consist of Mimosaceae, Combretaceae, Euphorbiaceae, Caesalpiniaceae, Rubiaceae, Tiliaceae, Anacardiaceae, Fabaceae, Meliaceae, Bignoniaceae, Sapotaceae and Olacaceae etc.

\section{Sampling Approach}

We adopted the random sampling method for our study (Gibbs et al., 2007). First, the vegetation at both sites was divided into different types: (i) gallery forests, (ii) woodland savannas, (iii) tree savannas, and (iv) shrub savannas, based on their floristic composition (Dimobe et al. 2014). Shrubs were defined as the multi-stemmed vegetation originating from the same root and having $\leq 2 \mathrm{~m}$ height. Referring to FAO standards when defining shrublands, the height limits for trees and shrubs should be interpreted with flexibility, particularly the minimum tree and maximum shrub height (FAO, 2004); that is why for the studied vegetation a rather low value was selected to closely match the characteristics. Due to the similarities in the floral composition of shrub and tree savannas, the shrub savannas were categorized by a shrub cover of approximately 75\% and above (Altamirano et al., 2013; Chojnacky \& Milton, 2008; Pfeifer et al., 2014).

Overall 40 plots were established at both sites, 5 plots each in every vegetation type at both sites. The plots had a size of $20 \mathrm{~m} \times 20 \mathrm{~m}$ each (Holdaway et al., 2014). Measuring tape was used to measure the sides of the plots, and on each side every time the tape was left for better identification of the boundaries. The area of each plot was 0.04 hectares (ha), and the total sampled area was 1.6 ha. The distance between plots was more than $100 \mathrm{~m}$ (Fischer et al., 2011). The tree and shrub individuals with a diameter at breast height (dbh) $\geq 5 \mathrm{~cm}$ were identified with the help of local botanists. 


\section{LAI estimation}

There were 16 hemispherical photographs were taken at each plot and 640 for overall 40 plots. These photographs were taken in dry season from February-March (Leblanc et al., 2005) to avoid an overlap with the transition into the wet season - due to resource limitations another distinct data set for the wet season could not be compiled yet.

The sampling scheme for digital hemispherical photography was adopted according to Fig. 1. Before the start of the hemispherical photography, plots were cleared from any obstacles closer than $0.5 \mathrm{~m}$ to the camera lens at any photo point to minimize measurement errors. Similarly, care was taken so that the fisheye lens would not be obscured by the tall grasses (Chianucci \& Cutini, 2013). The photographs were taken with Nikon ${ }^{\mathrm{TM}}$ Coolpix 4500 digital camera which had a Nikon ${ }^{\mathrm{TM}}$ FC-E8 fisheye converter mounted on a stand $1.3 \mathrm{~m}$ above ground level (Lindner \& Sattler, 2012). The vegetation above 1.3m (camera height) was photographed and considered for LAI estimation. The understorey vegetation (grasses etc.) was, therefore, excluded from the estimation and was also not a part of the study. The aperture and shutter speed of the camera was adjusted to automatic mode. The photographs were auto-exposed. The tripod was always levelled with the help of spirit level present on the top side of the tripod before taking the photographs (Liu et al., 2013). The camera was always aligned to the North with the help of a magnetic compass before every photograph (Olivas et al., 2013). The photographs (Fig. 2) were taken by the same person so that the same protocol could be followed throughout (Ryu et al., 2010).

Fig. 1: Digital hemispherical photography order adopted in the $20 \mathrm{~m} \times 20 \mathrm{~m}$ size plots, the arrows showing the direction of taking photographs in the plots and the red dots shows the position of hemispherical photography points. The distances with the boundaries were kept at $\mathbf{2 . 5} \mathrm{m}$ and the distances between different photography points were kept at 5 m.

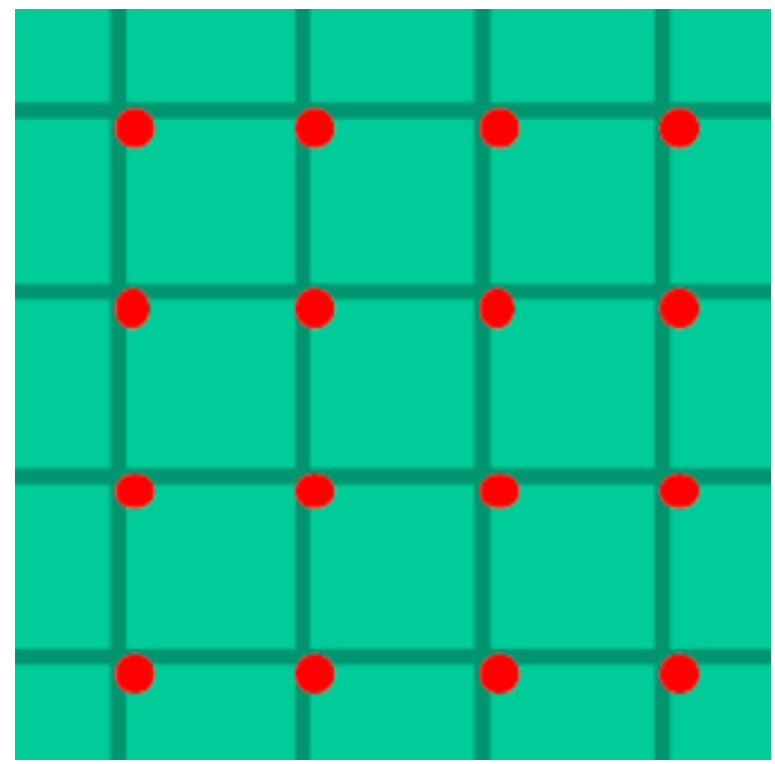


Fig. 2: Hemispherical photographs of woodland savannas (left: Nazinga Game Ranch; right: Bontioli Nature Reserve)
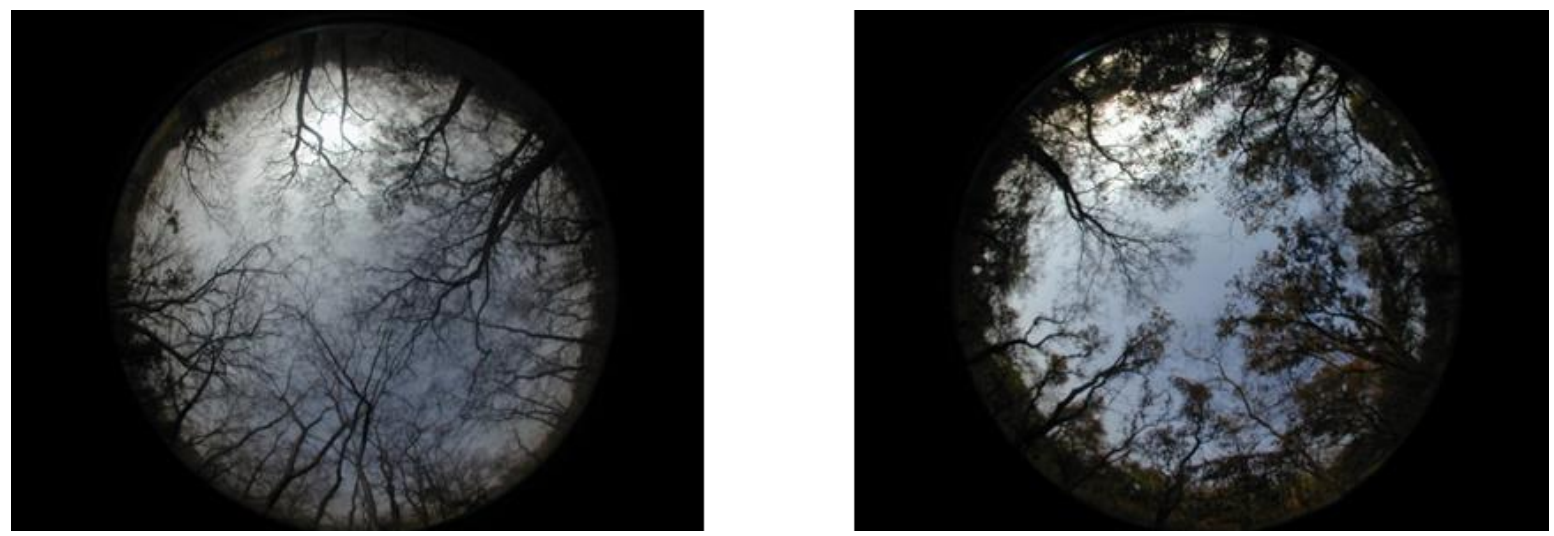

The WinScanopy 2005ab software (Regent Instruments Inc., 2005) was used to analyze the hemispherical photographs and to derive data about canopy openness (CO) and LAI. For the camera and lens used, the according calibration file by Regent Instruments Inc. was used. Canopy openness is defined as the proportion of open sky area in a $180^{\circ}$ hemisphere monitored from a centre point. Pixels of digital images are to be classified as either "canopy" or "sky" based on the grayscale threshold value. Hereby the automatic global threshold pixels classification method provided by the software was used. The LI-COR LAI2000 modified algorithm (assuming random leaf distribution, transmittance is equivalent to gap fraction, modelled by the Poisson model) was used to calculate LAI values (Welles \& Norman, 1991).

\section{Crown Diameter Estimation}

Crown diameters (CD) are the average of the lengths of longest spread from edge to edge across the crown and the longest spread perpendicular to the first cross-section through the central mass of the crown (Blozan 2006, Scholes et al., 2004). Measurements were taken independently of trunk positions. The CDs measurements were taken in the same sampling plots as described above for LAI estimations. An average value for both the CDs was calculated in meters for each tree and shrub in every plot.

\section{Statistical Analysis}

All the means and standard deviations were calculated for LAI and CD per plot. To assess the normality of mean LAI and CD across both sites, the Shapiro Wilk-Normality Test $(S-W)$ was used. The mean LAI and mean CD were not normally distributed. The non-parametric tests, the Wilcoxon Rank Sum Test $(W)$ and the Kruskal Wallis Rank Sum Test $(K-W)$ were used (Oliveira et al., 2014). The Wilcoxon Rank Sum Test $(W)$ was used to compare the LAI for the two sites. The Kruskal Wallis Rank Sum Test $(K-W)$ was used for the comparison of LAI and CD across four vegetation types at both sites. The post-hoc Tukey's Honest Significant Difference (HSD) Test was used for seeing differences between vegetation types in pairs after using the Kruskal Wallis Rank Sum Test $(K-W)$ for the LAI across four vegetation types at two sites. Boxplots in figures were presented on the base of median values instead of means for LAI, to provide an extended view on the range of data distribution. A confidence interval of $95 \%$ (significance level of 0.05 ) was used for all the statistical 
analysis. All statistical analysis was performed using the version 3.1.0 of R (R Core Team 2014).

\section{RESULTS}

The LAI values for Nazinga Game Ranch and Bontioli Nature Reserve were recorded in the ranges of 0.01-1.32 and 0.01-1.33 respectively. The LAI across the two sites of Nazinga Game Ranch and Bontioli Nature Reserve was not statistically different from each other (Fig. $3)$.

Fig. 3: LAI distribution across two sites. The bold horizontal line per box represents the median. The figure also shows the statistical comparison of LAI between the two sites: LAI across the two sites of Nazinga Game Ranch and Bontioli Nature Reserve was not statistically different from each other. The LAI data was also not normally distributed $(S-W=0.86, p<0.05)$.

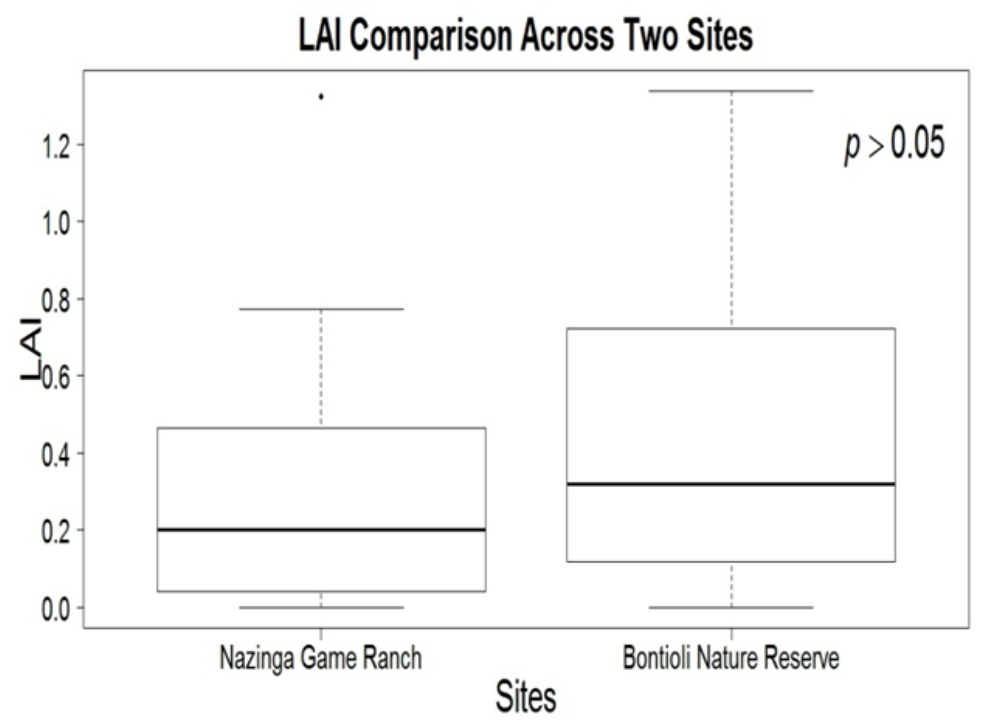

The gallery forest showed the highest mean LAI of $1.33 \pm 0.32$ (median: 0.81 ), whereas the shrub savanna showed the lowest mean LAI of $0.02 \pm 0.02$ (median: 0.02 ) across the two sites (Fig. 4). Statistical differences were also recorded in LAI among different vegetation types across the two sites though (Fig. 4); except that there were no significant differences among tree savanna and shrub savanna $(p>0.05)$ and between woodland savanna and tree savanna $(p>0.05)$.

CD was significantly different among different vegetation types across the two sites though (Table 1). 
Fig. 4: LAI distribution across vegetation types at the two sites. The bold horizontal line per box represents the median. Statistical differences were recorded in LAI among different vegetation types; except there was no significant difference among tree savanna and shrub savanna and between woodland savanna and tree savanna.

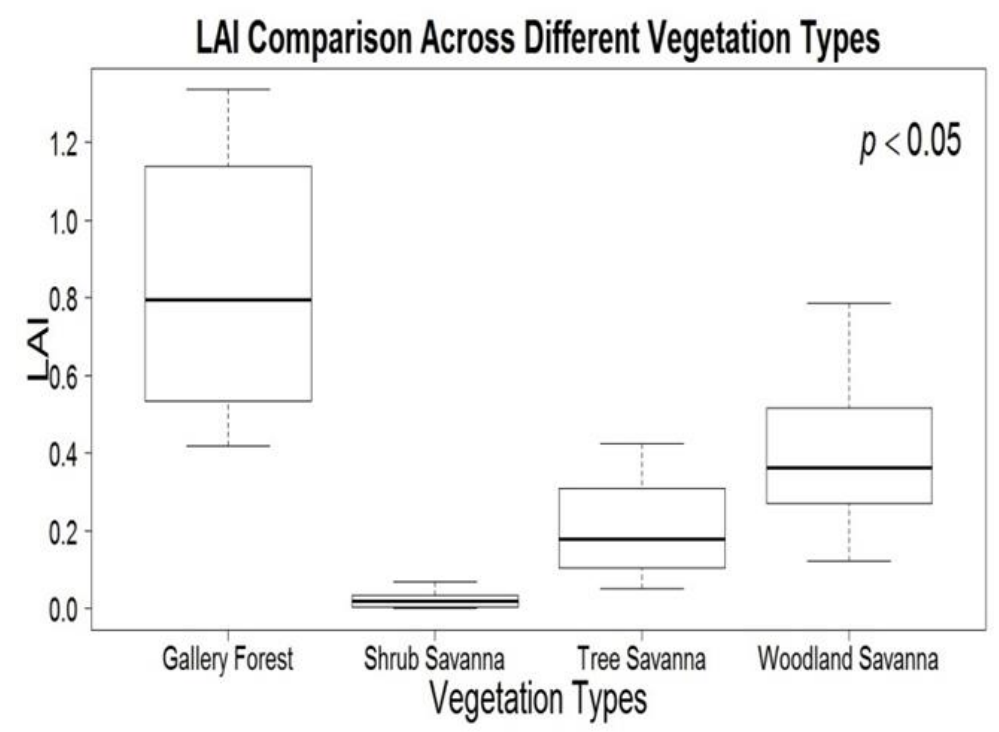

Table 1: Canopy diameter (CD) across different vegetation types at Nazinga Game Ranch and Bontioli Nature Reserve.

\begin{tabular}{|c|c|c|c|c|}
\hline Vegetation Types & $\mathrm{CD}(\mathrm{m})$ & & & \\
\hline & Mean* & SD $^{\mathbf{a}}$ & Max & Min \\
\hline Woodland Savanna & 4.89 & \pm 1.46 & 6.85 & 2.12 \\
\hline Tree Savanna & 2.09 & \pm 0.88 & 3.26 & 1.04 \\
\hline Shrub Savanna & 1.15 & \pm 0.44 & 1.64 & 0.46 \\
\hline Gallery Forest & 7.69 & \pm 1.90 & 11.01 & 4.41 \\
\hline
\end{tabular}

\section{DISCUSSION}

According to our research, only two studies related to LAI estimation have been conducted in Bontioli Nature Reserve alone. In one of the studies, Tia (2007) had reported LAI values of $3.10 \pm 1.02($ mean $\pm \mathrm{SD}$ ) (rainy season) (September 2005) and $0.57 \pm 1.27$ (mean \pm SD) (dry season) (May 2006) for Shrub Savannas and $2.59 \pm 0.73$ (mean \pm SD) (rainy season) (September 2005) and $1.05 \pm 0.72($ mean \pm SD) (dry season) (April 2006) for Tree Savannas. No LAI values for other vegetation types were reported from Bontioli Nature Reserve. Tia (2007), however, mainly attributed their higher LAI values for shrub savannas to the competing tall grasses of more than $3 \mathrm{~m}$ in height. Our studydid not consider the grasses for 
LAI estimation in any of the vegetation type. Tia (2007) also pointed out that lower values of LAI can be observed in the dry seasons. Our study estimates LAI for the dry season. LAI thus can be variable within a year and within different seasons and therefore has different responses to various land cover changes and moreover, it can also be variable between different locations (Scholes et al., 2004).

Another study of Ky-Dembele et al. (2014) reported LAI values in the range of 1-5.7 with a mean of 3.2 for Bontioli Nature Reserve. Brümmer et al. (2008) recorded these values in September 2005, a wet season in Bontioli Nature Reserve, again could be the reason why LAI values at higher end when compared to our study. Wagner et al. (2009) had reported LAI values ranging from 0.5-1.5 for the dry season (November and April) for the northern part of the White Volta catchment situated upstream of Lake Volta in Northern Ghana and Burkina Faso. Wagner et al. (2009) also reported the LAI values for rainy season (May-October) for the southern part of the same catchment which ranged between 0.5-2.5. A contrast between the dry season and wet season can also be noticed in the results of Wagner et al. (2009).

It was observed during the dry season that tree species had lost their leaves and their crowns did not seem dense. The LAI values were recorded in the range of $0-1.33$ for this study for both the sides during this dry season. It is therefore expected that LAI values will be at their higher values in the wet season, from May to October, in the site areas (Grote et al., 2009). Not much variation was recorded between the two sites. The results for the LAI estimation showed that the difference between the two sites is also not statistically significant (Fig. 1). Both of the sites are the representation of a similar agro-ecological zone, Southern Sudanian Savanna, having a pronounced dry season of 4-6 months with 1000-1200 mm of annual rainfall (Ky-Dembele et al., 2014; Ministry of Environment and Sustainable Development, 2013). The climatic conditions of both sites are similar and the site conditions were also not found to be of much difference as observed.

The LAI estimates, however, were significantly different when comparing the vegetation types (Fig. 2). In gallery forests there was the highest mean LAI, $1.33 \pm 0.32$ (median: 0.81 ), comparing to the other vegetation types. This could be due to overall bigger and denser crown sizes compared to the other vegetation types. The shape and structure of crown can give an indication of the amount of the light penetration through these crowns which in turn can help in identification of the site competition and the growth of the vegetation. Light, as we know, is an important factor for the growth and vitality of the trees (Johansson, 1996). The other attribute, $\mathrm{CD}$, also emphasized this factor. The results also showed that gallery forests had the highest $\mathrm{CD}, 7.69 \pm 1.90 \mathrm{~m}$, comparing to the other vegetation types.

LAI is one of the most important parameter of forest structure (Biudes et al., 2014). However, there is a deficiency of LAI data from the tropical regions, especially across degraded vegetation types (Altamirano et al., 2013). But continuous monitoring of LAI is challenging and requires frequent visits (Gonsamo \& Chen, 2014). The indirect measurements, such as the use of allometric equations, therefore, can prove useful for LAI estimations (Jonckheere et al., 2004).

Our study was the first attempt in Nazinga Game Ranch, for which no study on LAI estimation to our knowledge exists. However, for in depth understanding of LAI at these two sites, studies in winter season are highly recommended. We can say that during this season the vegetation is lush green and therefore inclusion of LAI estimations from this season is a must. Nevertheless, LAI estimations from dry season can also provide a good comparison with the LAI values for winter season and could initiate a good discussion towards the LAI characteristics of different vegetation types at these two sites for the two seasons. Long term LAI monitoring is considered important for the overall management of the vegetation. Now with the challenges of climate change, the researches of forest structures and their 
compositions and inter-linkages between their various bio-physical parameters have also become essential. The better understanding of which can assist in monitoring and drawing better strategies for a sustainable forest and savanna management (Dimobe et al., 2015).

\section{ACKNOWLEDGEMENTS}

We are thankful to the DAAD (German Academic Exchange Service) for the financial support and the West African Science Service Centre on Climate Change and Adapted Land Use (WASCAL) Programme for their logistic support. We are indebted to Mr. Kangbeni Dimobe for the help in identifying the tree and shrub species. The study was part of the fulfillment for the MSc.-degree in Tropical Forestry of Mahommad Qasim. This research contributes to Research Cluster 2 (Landscape Dynamics) and Work Package 2.7 (Biodiversity and Ecosystem Services) of the WASCAL Programme. We are grateful for the comments of the editor and reviewers, which greatly improved the manuscript.

\section{REFERENCES}

Altamirano, A., Aplin, P., Miranda, A., Cayuela, L., Algar, A. C., \& R. Field, (2013). High rates of forest loss and turnover obscured by classical landscape measures. Applied Geography 40: 199-211.

Arias, D., Calvo-Alvarado, J., \& A. Dohrenbusch, (2007). Calibration of LAI-2000 to estimate leaf area index (LAI) and assessment of its relationship with stand productivity in six native and introduced tree species in Costa Rica. Forest Ecology and Management 247: 185-193.

Biudes, M. S., Machado, N. G., de Morais Danelichen, V. H., Souza, M. C., Vourlitis, G. L., \& J. de Souza Nogueira (2014). Ground and remote sensing-based measurements of leaf area index in a transitional forest and seasonal flooded forest in Brazil. International journal of biometeorology 58: 1181-1193.

Blozan, W. (2006). Tree measuring guidelines of the eastern native tree society. Bulletin of the Eastern Native Tree Society 1: 3-10.

Brümmer, C., Falk, U., Papen, H., Szarzynski, J., Wassmann, R., \& N. Brüggemann, (2008). Diurnal, seasonal and interannual variation in carbon dioxide and energy exchange in shrub savanna in Burkina Faso (West Africa). Journal of Geophysical Research 113: G02030

Chen, J. M. \& T. A. Black (1992). Defining leaf area index for non-flat leaves. Plant, Cell \& Environment 15: 421-429.

Chianucci, F. \& A., Cutini (2013). Estimation of canopy properties in deciduous forests with digital hemispherical and cover photography. Agricultural and Forest Meteorology 168: 130-139.

Chojnacky, D. C. \& Milton, M. (2008). Measuring carbon in shrubs. pp. 45-72. In: C. M. Hoover (ed.) Field measurements of forest carbon monitoring: A landscape-scale approach. Springer, Durham, USA.

Dekker, A. J. F. (1985). Carte de paysage de la région du Ranch de Gibier de Nazinga, Burkina Faso. Ouagadougou.

Dimobe, K., Wala, K., Dourma, M., Kiki, M., Woegan, Y., Folega, F., Batawila, K. \& K. Akpagana, (2014). Disturbance and population structure of plant communities in the wildlife reserve of Oti-Mandouri in Togo (West Africa). Annual Research \& Review in Biology 4: 
2501-2516.

Dimobe, K., Ouedraogo, A., Soma, S., Goetze, D., Porembski, S., \& A. Thiombiano, (2015). Identification of driving factors of land degradation and deforestation in the Wildlife Reserve of Bontioli (Burkina Faso, West Africa). Global Ecology and Conservation 4: 559-571.

FAO (2004). National Forest Inventory - Field Manual Template (4rd Edition). FAO Forestry Department. Rome

Fieber, K. D., Davenport, I. J., Tanase, M. A., Ferryman, J. M., Gurney, R. J., Walker, J. P. \& J. M. Hacker (2014). Effective LAI and CHP of a Single Tree From Small-Footprint Full-Waveform LiDAR. IEEE Geoscience and Remote Sensing Letters 11: 1634-1638.

Fischer, C., Kleinn, C., Fehrmann, L., Fuchs, H. \& O. Panferov (2011). A national level forest resource assessment for Burkina Faso-A field based forest inventory in a semiarid environment combining small sample size with large observation plots. Forest Ecology and Management 262: 1532-1540.

Gibbs, H. K., Brown, S., Niles, J. O. \& J. A. Foley, (2007). Monitoring and estimating tropical forest carbon stocks: making REDD a reality. Environmental Research Letters 2: 045023.

Gonsamo, A. \& J. M. Chen, (2014). Continuation observation of leaf area index at Fluxnet-Canada sites. Agricultural and Forest Meteorology 189-190: 168-174.

Grote, R., Lehmann, E., Brümmer, C., Brüggemann, N., Szarzynski, J. \& H. Kunstmann, (2009). Modelling and observation of biosphere-atmosphere interactions in natural savannah in Burkina Faso, West Africa. Physics and Chemistry of the Earth, Parts A/B/C 34: 251-260.

Hema, E. M., Barnes, R. F. \& W. Guenda, (2011). Distribution of savannah elephants (Loxodonta africana africana Blumenbach 1797) within Nazinga game ranch, Southern Burkina Faso. African Journal of Ecology 49: 141-149.

Holdaway, R. J., McNeill, S. J., Mason, N. W., \& F. E. Carswell, (2014). Propagating uncertainty in plot-based estimates of forest carbon stock and carbon stock change. Ecosystems 17: 627-640.

Jenks, J. A., Klaver, R. W., \& Z. W. Wicks III., (2007). Determinants of elephant distribution at Nazinga Game Ranch, Burkina Faso. Pachyderm 42: 70-80.

Johansson, T., (1996). Estimation of canopy density and irradiance in 20 to 40 year old Birch stands (Betula pubescens Ehrh. Betula pendula Roth). Trees 10: 223-230.

Jonckheere, I., Fleck, S., Nackaerts, K., Muys, B., Coppin, B., Weiss, M. \& F. Baret, (2004). Review of methods for in situ leaf area index determination - Part I. Theories, sensors and hemispherical photography. Agricultural and Forest Meteorology 121: 19-35.

Khosravi, S., Namiranian, M., Ghazanfari, H. \& A. Shirvani (2012). Estimation of leaf area index and assessment of its allometric equations in Oak forests: Northern Zagros, Iran. Journal of Forest Science 58: 116-122.

Kristensen, M. \& H. Balslev, (2003). Perceptions, use and availability of woody plants among the Gourounsi in Burkina Faso. Biodiversity \& Conservation 12: 1715-1739.

Ky-Dembele, C., Tigabu, M., Bayala, J. \& P. C. Odén, (2014). Inter- and intra-provenances variations in seed size and seedling characteristics of Khaya senegalensis A. Juss in Burkina Faso. Agroforestry systems 88: 311-320.

Leblanc, S. G., Chen, J. M., Fernandes, R., Deering, D. W. \& A. Conley, (2005). Methodology comparison for canopy structure parameters extraction from digital 
hemispherical photography in Boreal forests. Agricultural and Forest Meteorology 129: 187-207.

Lindner, A. \& D. Sattler, (2012). Biomass estimations in forests of different disturbance history in the Atlantic Forest of Rio de Janeiro, Brazil. New Forests 43: 287-301.

Lindner, A. (2011). Small structure of forest stands in the Atlantic Rainforest - Notes on understory light fluctuation. Tropical Ecology 52(2): 139-150.

Liu, C., Kang, S., Li, F., Li, S. \& Du, T., (2013). Canopy leaf area index for apple tree using hemispherical photography in arid region. Scientia Horticulturae 164: 610-615.

Ministry of Environment and Sustainable Development, (2011). Forest Investment Program - Burkina Faso. Ministry of Environment and Sustainable Development, Ouagadougou.

Moniod, F., Pouyaud, B. \& P. Sechet, (1977). Le bassin du fleuve Volta. Monographies hydrologiques. ORSTOM, Paris.

MSP, (2010). Meteorological Station of Pô, Burkina Faso. Direction de la Météorologie du Burkina, Ouagadougou.

Mustafa, Y. T., Tolpekin, V. A. \& A. Stein, (2014). Improvement of Spatio-temporal Growth Estimates in Heterogeneous Forests Using Gaussian Bayesian Networks. Geoscience and Remote Sensing, IEEE Transactions 52: 4980-4991.

Nfon, E., Armitage, J. M. \& I. T. Cousins, (2011). Development of a dynamic model for estimating the food web transfer of chemicals in small aquatic ecosystems. Science of the Total Environment 409: 5416-5422.

Olivas, P. C., Oberbauer, S. F., Clark, D. B., Clark, D. A., Ryan, M. G., O’Brien, J. J. \& H. Ordonez, (2013). Comparison of direct and indirect methods for assessing leaf area index across a tropical rain forest landscape. Agricultural and Forest Meteorology 177: 110-116.

Oliveira, A. P. D., Schiavini, I., Vale, V. S. D., Lopes, S. D. F., Arantes, C. D. S., Gusson, A. E., Júnior, J. A. P. \& O. C. Dias-Neto, (2014). Mortality, recruitment and growth of the trees communities in three forest formations at the Panga Ecological Station over ten years (1997-2007). Acta Botanica Brasilica 28: 234-248.

Pfeifer, M., Lefebvre, V., Gonsamo, A., Pellikka, P. K., Marchant, R., Denu, D. \& P. J. Platts, (2014). Validating and Linking the GIMMS Leaf Area Index (LAI3g) with Environmental Controls in Tropical Africa. Remote Sensing 6: 1973-1990.

Pompelli, M. F., Antunes, W. C., Ferreira, D. T. R. G., Cavalcante, P. G. S., Wanderley-Filho, H. C. L. \& L. Endres, (2012). Allometric models for non-destructive leaf area index estimation of Jatropha curcas. Biomass and bioenergy 36: 77-85.

R Core Team, (2014). A Language and Environment for Statistical Computing. R Foundation for Statistical Computing, Vienna.

Regent Instruments Inc., (2005). WinScanopy 2005ab for hemispherical image analyses. Retrieved August 6, 2015, from http//www.regentinstruments.com.

Ryu, Y., Sonnentag, O., Nilson, T., Vargas, R., Kobayashi, H., Wenk, R. \& D. D. Baldocchi, (2010). How to quantify tree leaf area index in an open savanna ecosystem: a multi-instrument and multi-model approach. Agricultural and Forest Meteorology 150: 6376.

Scholes, R. J., Frost, P. G. \& Y. Tian, (2004). Canopy structure in savannas along a moisture gradient on Kalahari sands. Global Change Biology 10: 292-302.

Tia, L., (2007). Modelling of vegetation dynamics and its contribution to the water balance of in semi-arid lands of West Africa. ZEF, Bonn. 
Unger, M., Homeier, J. \& C. Leuschner, (2013). Relationship among leaf area index, below canopy light availability and tree diversity along a transect from tropical lowland to montane forests in NE Ecuador. Tropical Ecology 54(1): 33-45.

Vermeulen, C., Lejeune, P., Bouché, P., Marchal, A., Ouédraogo, M., Sawadogo, P., Yaméogo, D.-D. \& F. Yanogo, (2012). Status of medium-sized ungulate populations in 2010, at the Nazinga Game Ranch, Burkina Faso (West Africa). Biotechnological, Agronomy, Society and Environment 16: 307-315.

Von Buschfeuern, S. K. D. V., (2010). Mapping Bushfire Distribution and Burn Severity in West Africa Using Remote Sensing Observations. PhD Thesis. University of Würzburg, Würzburg.

Vyas, D., Mehta, N., Dinakaran, J. \& N. S. R. Krishnayya, (2010). Allometric equations for estimating leaf area index (LAI) of two important tropical species (Tectona grandis and Dendrocalamus stricta). Journal of Forestry Research 21: 197-200.

Wagner, S., Kunstmann, H., Bárdossy, A., Conrad, C. \& R. R. Colditz, (2009). Water balance estimation of a poorly gauged catchment in West Africa using dynamically downscaled meteorological fields and remote sensing information. Physics and Chemistry of the Earth, Parts A/B/C 34: 225-235.

Weiss, M., Baret, F., Smith, G. J., Jonckheere, I. \& P. Coppin, (2004). Review of methods for in situ leaf area index determination. Part II. Estimation of LAI, errors and sampling. Agricultural and Forest Meteorology 121: 37-53.

Welles, J. M. \& J. M. Norman, (1991). Instrument for indirect measurement of canopy architecture. Agronomy Journal 83: 818-825.

Zhao, D., Lv, M., Wang, P., Yang, T. \& S. An, (2014). Can the plant area index of a submerged vegetation canopy be estimated using digital hemispherical photography? Agricultural and Forest Meteorology 192: 69-77. 
Journal of Landscape Ecology (2016), Vol: 9 / No. 1

Annex 1: Cumulative species list of all determined shrubs and trees $(\mathrm{dbh} \geq 5 \mathrm{~cm})$ at Nazinga Game Ranch and Bontioli Nature Reserve

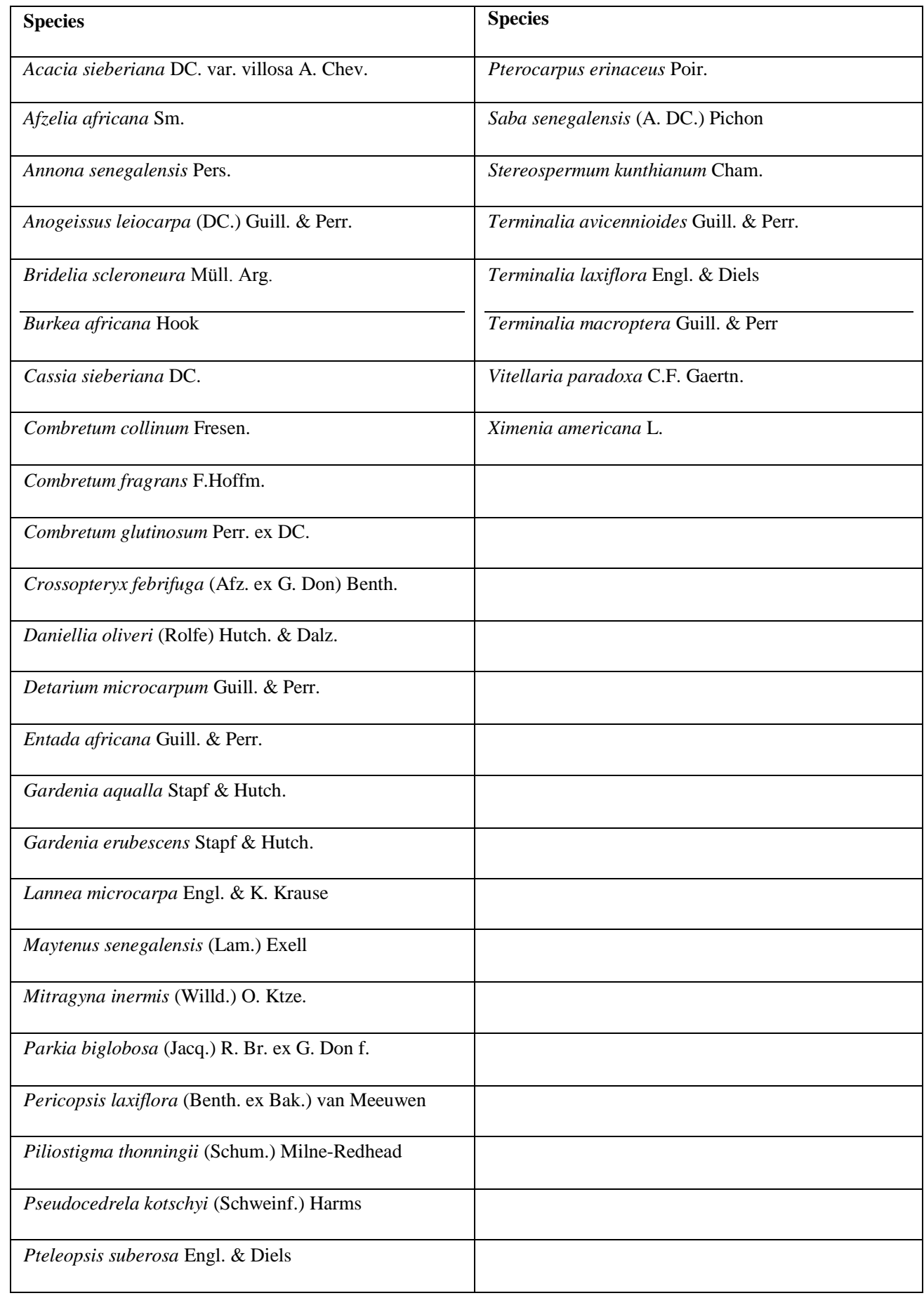

